\title{
REHABILITASI PSIKOSOSIAL UNTUK MEWUJUDKAN ORANG DENGAN GANGGUAN JIWABERMARTABAT DI WILAYAH KERJA PUSKESMAS SUNGGAL MEDAN
}

\author{
Jenny Marlindawani Purba ${ }^{1}$, Sri Eka Wahyuni ${ }^{2}$, Mahnum Lailan Nasution ${ }^{3}$, \\ Evi Karota ${ }^{4}$ \\ ${ }^{1-4}$ Fakultas keperawatan Universitas Sumatera Utara \\ Email Korespondensi: jenny_marlindawani@usu.ac.id
}

Disubmit: 27 September 2021 Diterima: 4 Desember $2021 \quad$ Diterbitkan: 01 Januari 2022 DOI: https://doi.org/10.33024/jkpm.v1i1.5185

\begin{abstract}
ABSTRAK
Peningkatan kasus COVID 19 dan penerapan pemberlakuan pembatasan kegiatan masyarakat di Kota Medan mengakibatkan kegiatan pelayanan kesehatan jiwa masyarakat terhenti. Salah satu prioritas masalah di wilayah kerja Puskesmas Sunggal adalah gangguan jiwa. Situasi saat ini banyak penderita yang tidak teratur minum obat, tidak kontrol ke puskesmas atau rumah sakit, mengalami kekambuhan dan tidak mematuhi protokol kesehatan bila keluar rumah serta tidak produktif. Kegiatan ini bertujuan untuk meningkatkan fungsi sosial dan keterampilan orang dengan gangguan jiwa. Target khusus yang ingin dicapai adalah perubahan perilaku dari ODGJ dan keluarga di wilayah kerja Puskesmas Sunggal Medan. Metode yang digunakan adalah ceramah, diskusi dan tanya jawab, home visit, pengembangan bakat dan minat pasien berupa pelatihan dan pendampingan pembuatan sabun cair. Hasil yang diperoleh dari kegiatan ini adalah 12 orang dari 15 ODGJ (80\%) dapat mengontrol gejala pskotik, kontrol teratur ke puskesmas sebelum obat habis dan mempunyai keterampilan membuat sabun cair serta mampu mengembangkan keterampilan lainnya sesuai dengan minat dan bakat masingmasing. Rehabilitasi psikosoial memberikan dampak positif bagi peningkatan fungsi kognitif, psikomotor dan afektif orang dengan gangguan jiwa. Keberhasilan program ini membutuhkan partisipasi aktif dari semua pihak.
\end{abstract}

Kata Kunci : Rehabilitasi, psikososial, orang dengan gangguan jiwa, bermartabat

\section{ABSTRACT}

The increase in cases of COVID 19 and the implementation of restrictions on community activities in the city of Medan resulted in community mental health service activities being stopped. One of the priority problems in the work area of the Sunggal Health Center is mental disorders. The current situation was people with mental illness did not regularly take medication, did not go to the community health center or hospital to see the Doctor, experience relapses and did not comply with health protocols when leaving the house, and was unproductive. The activity aims to improve the social functioning and skills of people with mental disorders. The specific target to be achieved is to change the behavior of ODGJ and their families in the working area of the Sunggal Community Health Center, Medan. The methods used were lectures, discussions and questions and answers, home visits, identifying talents and interests of 
patients in the form of training and assistance in making liquid soap. The results of the activities were 12 from 15 of people with mental illness (80@) can control psychotic symptoms, regularly visit "the puskesmas" before the drugs run out and have the skills to make liquid soap, and are able to develop other skills according to their respective interests and talents. Psychosocial rehabilitation has a positive impact on improving the cognitive, psychomotor, and affective functions of people with mental disorders. The success of this program requires the active participation of all parties.

Keywords: rehabilitation, psychosocial, people with mental illness, dignity

\section{PENDAHULUAN}

Orang dengan gangguan jiwa masih diasumsikan sebagai beban keluarga dan masyarakat (Purba, Simamora \& Ginting, 2018). Hal ini disebabkan karena sebagian besar kelaurga khususnya caregiver masih memiliki pengetahuan yang tidak adekuat dan keterampilan yang kurang untuk merawat anggota kelaurga yang menderita gangguan jiwa (Magaru, 2012). Persepsi masyarakat terhadap penderita gangguan jiwa masih negatif dan dipandang sebelah mata. Masyarakat menganggap penderita gangguan jiwa adalah sampah sosial, dihina dan dicaci maki, serta tidak jarang penderita mendapatkan perlakuan yang tidak selayaknya didapatkan oleh manusia (Wardhani \& Asyanti, 2013).

Hawari (2012) mengemukakan bahwa salah satu kendala dalam upaya penyembuhan pasien gangguan adalah pengetahuan keluarga yang tidak adekuat. Keluarga menganggap gangguan jiwa penyakit yang memalukan dan membawa aib bagi keluarga. Masyarakat juga sering ditemukan berperilaku tidak menyenangkan kepada keluarga dari penderita gangguan jiwa baik secara perkataan maupun perbuatan langsung yang ditujukan kepada keluargamaupun penderita gangguan jiwa.

Pemberdayaan orang dengan gangguan jiwa sangat dibutuhkan untuk mengurangi beban perawatan yang dirasakan keluarga dan mengatasi stigma masyarakat. Mereka membutuhkan keterampilan untuk menjadikan mereka bermartabat. Oleh karena itu dibutuhkan rehabilitasi psikososial untuk meningkatkan fungsi kognitif, afektif, psikomotor dan sosial sehingga mereka dapat memenuhi kebutuhan sehari-hari serta mengurangi ketergantungan dengan keluarga. Rehabilitasi psikososial ini meliputi terapi kognitif dan pelatihan keterampilan sosial serta pelatihan untuk melakukan kegiatan seharihari di rumah yang terbukti dapat meningkatkan pengetahuan dan keterampilan sosial orang dengan gangguan jiwa kronis (Hafifah, Melyani Puspitasari \& Sinuraya, 2018; (Saha, Chauhan, Buch, Makwana, Vikar, Kotwani, \& Pandya, 2020). Penelitian yang dilakukan oleh Rasmus et al. (2021) menunjukkan bahwa program rehabilitasi psikososial dapat membantu mengatasi hambatan dan situasi yang sulit dengan menggunakan cara yang positif serta meningkatkan kemampuan patuh terhadap obat.

Dengan demikian, perlu dilaksanakan segera program kemitraan masyarakat dengan melibatkan tenaga kesehatan jiwa professional (Williams\& Tufford, 2012) untuk mengimplementasikan rehabilitasi psikososial dalam mewujudkan orang dengan gangguan jiwa yang bermartabat. Rehabilitasi adalah segala tindakan fisik, penyesuaian psikososial dan latihan vokasional sebagai usaha untuk memperoleh fungsi dan penyesuaian diri yang optimal serta mempersiapkan klien secara fisik, mental, sosial dan vokasional untuk suatu kehidupan penuh sesuai dengan kemampuannya (Pardede, 2019). Dengan 
rehabilitasi psikososial, ODGJ akan mencapai perbaikan fisik dan mental sebesar-besarnya, penyaluran dalam pekerjaan dengan kapasitas maksimal dan penyesuaian diri dalam hubungan perseorangan dan sosial sehingga bisa berfungsi sebagai anggota masyarakat yang mandiri dan berguna. Sehingga pasien dapat mengikuti kegiatan pelatihan untuk meningkatkan keterampilan mereka dalam memenuhi kebutuhan sehari-hari tanpa menjadi beban bagi keluarga.

\section{MASALAH}

Masalah kesehatan jiwa merupakan salah satu prioritas masalah kesehatan di wilayah kerja Puskesmas Sunggal Medan. Pandemi COVID 19 mengakibatkan kegiatan kesehatan jiwa masyarakat seperti pemberdayaan ODGJ dan kunjungan rumah tidak dapat dilaksanakan. Dampak yang ditimbukan dari pandemi ini adalah orang dengan gangguan jiwa menjadi tidak produktif, ketidakpatuhan minum obat meningkat, tidak kontrol ke Puskesmas untuk mengambil obat atau rujukan serta terjadinya peningkatan kekambuhan. Kegiatan rehabilitasi ini bertujuan untuk memberikan edukasi tentang kepatuhan minum obat, mengidentifikasi minat dan bakat, dan melakukan pendampingan dengam meberikan pelatihan dasar pembuatan sabun cair untuk cuci piring.

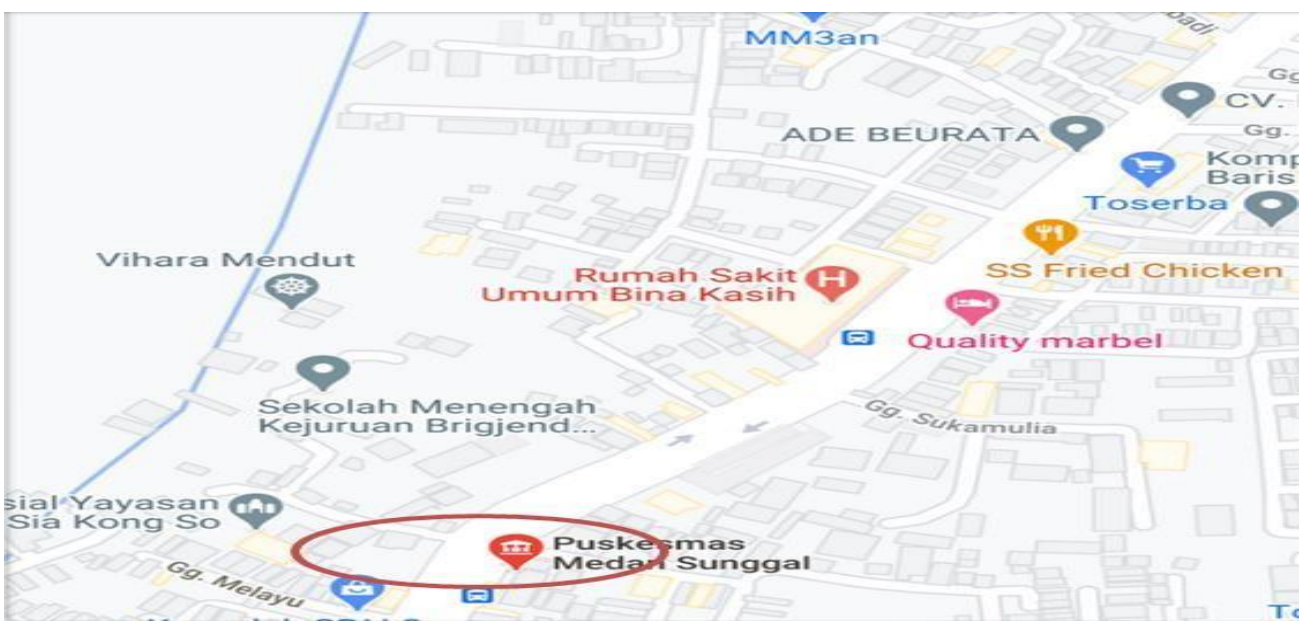

Gambar 2.1 Peta Lokasi Kegiatan Pengabdian Kepada Masyarakat.

\section{METODE}

a. Tujuan Persiapan

Tahap persiapan dimulai dari kordinasi dengan perawat kesehatan jiwa masyarakat dari Puskesmas Sunggal, Sekretaris Kelurahan Tanjung Rejo dan Kader Kesehatan Jiwa. Tim pelaksana dari Fakultas Keperawatan Universitas Sumatera Utara membuat perencanaan kegiatan berdasarkan hasil pengkajian lapangan, persiapan materi edukasi tentang obat, bahan dan alat yang digunakan untuk pelatihan pembuatan sabun cair dan pengembangan minat dan bakat. Kegiatan ini dilaksanakan di Aula Kelurahan Tanjung Rejo, Medan pada minggu pertama September 2021. 


\section{b. Tahap pelaksanaan}

Pelaksanaan kegiatan ini dimulai dengan perkenalan antara peserta, penjelasan tujuan kegiatan pengabdian kepada masyarakat dan melakukan teknik relaksasi tarik napas dalam. Peserta yang hadir dalam kegiatan ini sebanyak 30 orang yang terdiri dari kader kesehatan jiwa, orang dengan gangguan jiwa, perawat kesehatan jiwa masyarakat, bhabinkabtimas, staf kelurahan dan kepala lingkungan. Kegiatan kemudian dilanjutkan dengan pemberian edukasi tentang kepatuhan minum obat, pengembangan minat dan bakat, pelatihan pembuatan sabun cair dan diskusi serta tanya jawab. Ketua pelaksana juga menjelaskan mekanisme pelatihan yang harus ditaati oleh peserta.

c. Evaluasi

i. Struktur

Kegiatan pelatihan dasar pembuatan sabun cair dihadiri oleh 30orang yang terdiri dari orang dengan gangguan jiwa dengan pendampingan keluarga, kader kesehatan jiwa, Ibu Lurah Tanjung Rejo, perawat kesehatan jiwa masyarakat dari Puskesmas Sunggal, Bhabinkamtibmas dan mahasiswa Fakultas Keperawatan Universitas Sumatera Utara. pegawai Kantor Desa Romangloe. Pelatihan dilaksanakan di Aula Kelurahan Tanjung Rejo. Edukasi tentang obat, pengembangan minat dan bakat serta penjelasan pembuatan sabun cair disampaikan dengan jelas dan menggunakan bahasa yang mudah dimengerti oleh ODGJ khususnya. ODGJ sangat antusias mengikuti kegiatan ini dan dapat menjelaskan pentingnya minum obat dengan prinsip 8 benar (benar nama, benar obat, benar dosis, benar waktu, benar cara, benar tanggal kadaluarsa obat dan benar dokumentasi), menjelaskan bahan untuk pembuatan sabun cair,mendemonstrasikan pembuatan sabun cair dan melakukan pengemasan dengan baik dan benar. Keluarga juga terlibat aktif dan memberikan dukungan kepada ODGJ selama kegiatan berlangsung.

\section{ii. Proses}

Pelaksanaan kegiatan pukul $09.00 \mathrm{~s} / \mathrm{d} 12.00$ WIB. Kegiatanberlangsung sesuai dengan jadwal yang telah disepakati bersama.

\section{HASIL DAN PEMBAHASAN}

Hasil diskusi Tim Pelaksana kegiatan dengan perawat kesehatan jiwa masyarakat Puskesmas Sunggal ditemukan beberapa masalah yang dialamioleh orang dengan gangguan jiwa antara lain tidak datang ke puskesmas untuk mengambil obat, tidak ada kegiatan yang dilakukan oleh orang dengan gangguan jiwa (ODGJ) selama pandemi ini, terjadinya kekambuhan pada beberapa ODGJ yang mengharuskan untuk menjalani riwayat inap, ketidakpatuhan minum obat. Selain itu, masalah yang dialami oleh perawat kesehatan jiwa komunitas adalah terhentinya program kunjungan rumah yang diakibatkan adanya penerapan pembatasan kegiatan masyarakat (PPKM).

Keluarga menyampaikan beberapa hambatan yang ditemukan antara lain tidak mengijinkan anggota keluarga yang menderita gangguan jiwa untuk berobat ke puskesmas atau rumah sakit karena takur terpapar COVID-19, mereka tidak mengetahui apa yang harus dilakukan agar anggota keluarga yang 
sakit dapat melakukan kegiatan yang bermanfaat walaupun di masa pandemi ini. Keluarga mengeluh bahwa anggota keluarga yang sakit lebih banyak menghabiskan waktu dengan berdiam diri di rumah, malas, dan mempunyai hobi baru yaitu makan dan tidur. Tim pelaksana kegiatan PKM menggunakan beberapa metoda untuk membantu ODGJ dan keluarga dengan memberikan edukasi tentang pentingnya berobat secara teratur dan menganjurkan untuk patuh terhadap protokol kesehatan bila berkunjung ke puskesmas untuk berobat maupun mengambil surat rujukan.

Berdasarkan hasil pengkajian terhadap perawat kesehatan jiwa dan masyarakat dan keluarga tentang kebutuhan ODGJ dan keluarga maka tim pelaksana PKM menyusun beberapa perencanaan yang bertujuan untuk mewujudkan ODGJ bermartabat di wilayah kerja Puskesmas Sunggal.

Langkah pertama yang dilakukan adalah kordinasi dengan perawat kesehatan jiwa masyarakat untuk mengidentifikasi minat dan bakat dari ODGJ. Setelah itu, tim pelaksana PKM dengan dibantu oleh perawat jiwa dari puskesmas melakukan seleksi ODGJ yang akan diikutsertakan dalam pelatihan pembuatansabun cair. Beberapa hal yang dilakukan oleh tim pelaksana PKM saat proses seleksi yaitu dengan melakukan pengkajian terhadap riwayat penyakit, kemampuan, bakat dan minat ODGJ dengan pendampingan keluarga saat melakukan kunjungan rumah. Tim pelaksana PKM juga melibatkan kader kesehatan jiwa yang telah dilatih untuk menjelaskan proses pembuatan sabun cair ini.

Pemberian edukasi tentang obat, pengembangan minat dan bakat serta pelatihan pembuatan sabun cair merupakan bagian dari implementasi rehabilitasi psikososial. Kegiatan rehabilitasi psikososial ini merupakan suatu proses ditujukan untuk penderita gangguan jiwa kronis sebagai upaya memperbaiki fungsi ketergantungan, meningkatkan kualitas hidup (Saha et al., Pandya, 2020). serta meminimalkan faktor resiko terjadinya disabilitas sosial (Kalogerakis, Petroutsou, Chatzakis, Ploumpidis, Papageorgiou \& Economou, 2019). Pelatihan pembuatan sabun cair dilaksanakan untuk membantu ODGJ agar mereka dapat melihat hasil kreatifitas mereka yang dapat di jual ke masyarakat dengan harga terjangkau. Saat pelaksanaankegiatan pembuatan sabun cair terlebih dahulu tim pelaksana memperkenalkan diri dan menjelaskan tujuan dari kegiatan ini. KemudianTim pelaksana bersama kader mengajarkan latihan relaksasi sebelum kegiatandimulai. Setelah itu menjelaskan alat dan bahan yang digunakan untuk pembuatan sabun cair. Kemudian dilanjutkan dengan penjelasan tentang proses pembuatan sabun cair. Tim pelaksana meminta kepada ODGJ untuk mendemonstrasikan kegiatan ini. Kegiatan ini berlangsung selama dua hari. Selanjutnya, keesokan harinya tim pelksana bersama perawat jiwa dari puskesmas dan kader kesehatan jiwa kembali melanjutkan kegiatan proses pembuatan sabun cair. Pada hari kedua, setelah sabun cair yang sudah diolah dan didiamkan selama 24 jam kemudian dilanjutkan dengan proses pengemasan. Tim pelaksana mengajarkan cara memasukkan sabun cair ke dalam botol yang sudah disiapkan. Kegiatan pelatihan sabun cair ini diikuti oleh 15 orang ODGJ dengan pendampingan keluarga. Mereka sangat antusias dan senang mengikuti pelatihan ini karena dapat membuat sabun cair dan mempunyai kegiatan setelah selama ini hanya berdiam di rumah. Ibu Lurah berharap agar kegiatan pembuatan sabun cair dapat berlanjut sehingga ODGJ dapat produktif di era pandemi ini. Pada kesempatan ini keluarga juga menyambut baik dan menyatakan dukungan kepada ODGJ dalam melaksanakan kegiatan pembuatan sabun cair dan kegiatan lain yang bermanfaat baik ODGJ serta dapat mencegah kekambuhan. 
ODGJ juga dapat bersosialisasi dengan yang lainnya melalui kegiatan pelatihan ini. Selainitu, kegiatan yang dilakukan terkait dengan pengembangan minat dan bakat ODGJadalah kegiatan mewarnai, dimana tim pelaksana PKM memberikan bahan untuk diwarnai oleh ODGJ sehingga menghasilkan gambar yang menarik dengan perpaduan warna yang tepat. Hasil kegiatan pengabdian kepada masyarakat menunjukkan bahwa 12 orang dari 15 ODGJ (80\%) dapat mengontrol gejala pskotik, kontrol teratur ke puskesmas sebelum obat habis dan mempunyai keterampilan membuat sabun cairserta mampu mengembangkan keterampilan lainnya sesuai dengan minat dan bakat masing-masing. Berikut gambar pelaksanaan kegiatan:

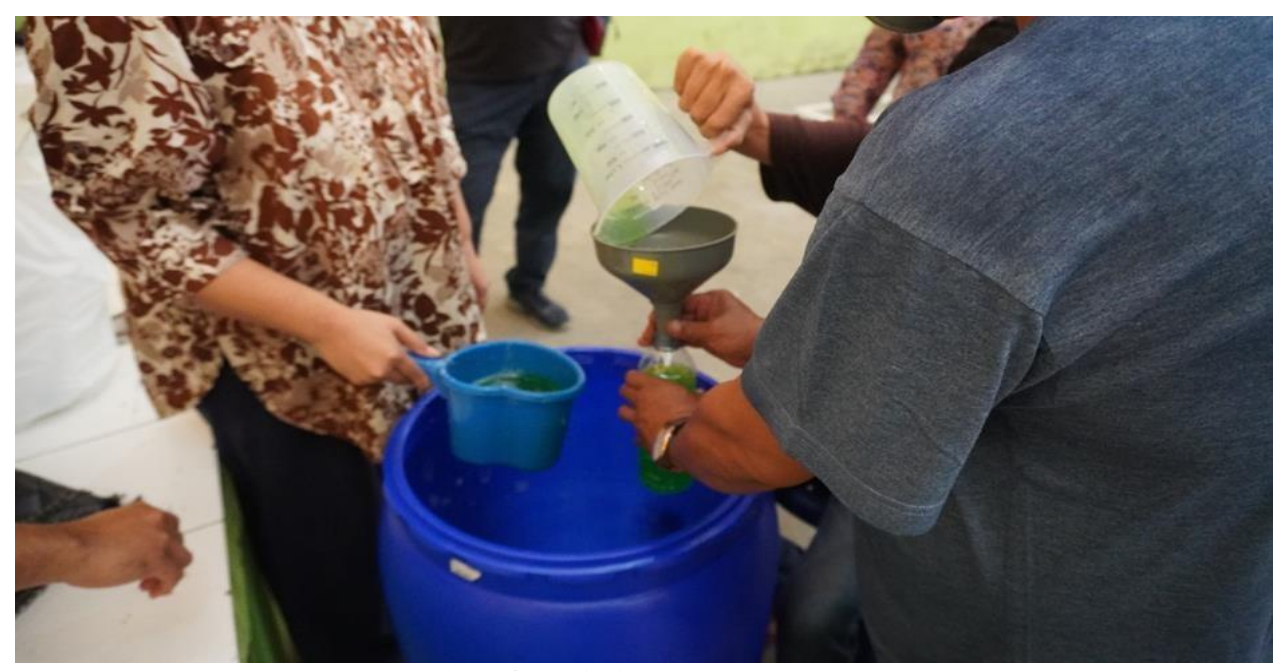

Gambar 2.2 Foto Kegiatan PKM

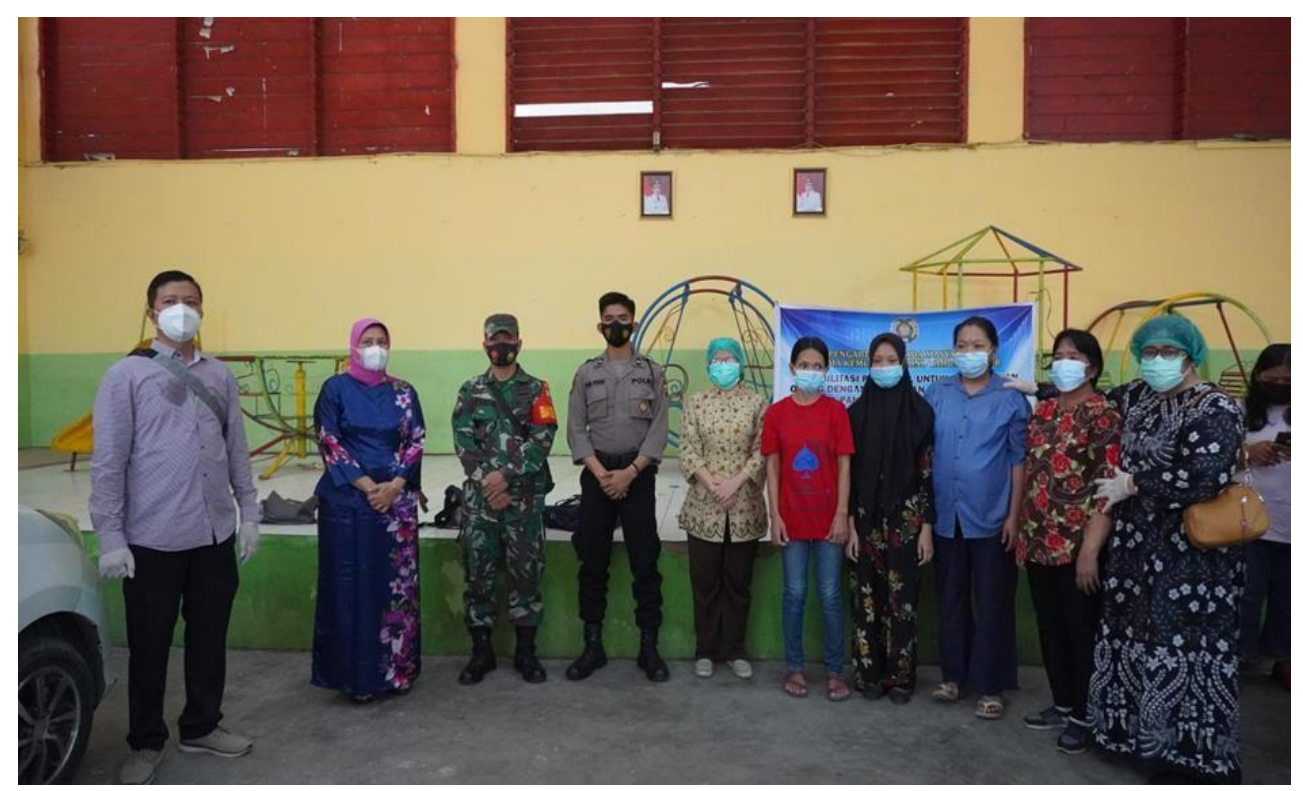

Gambar 2.3 Keterlibatan bhabinkamtibmas, Puskesmas danKelurahan Tanjung Rejo 


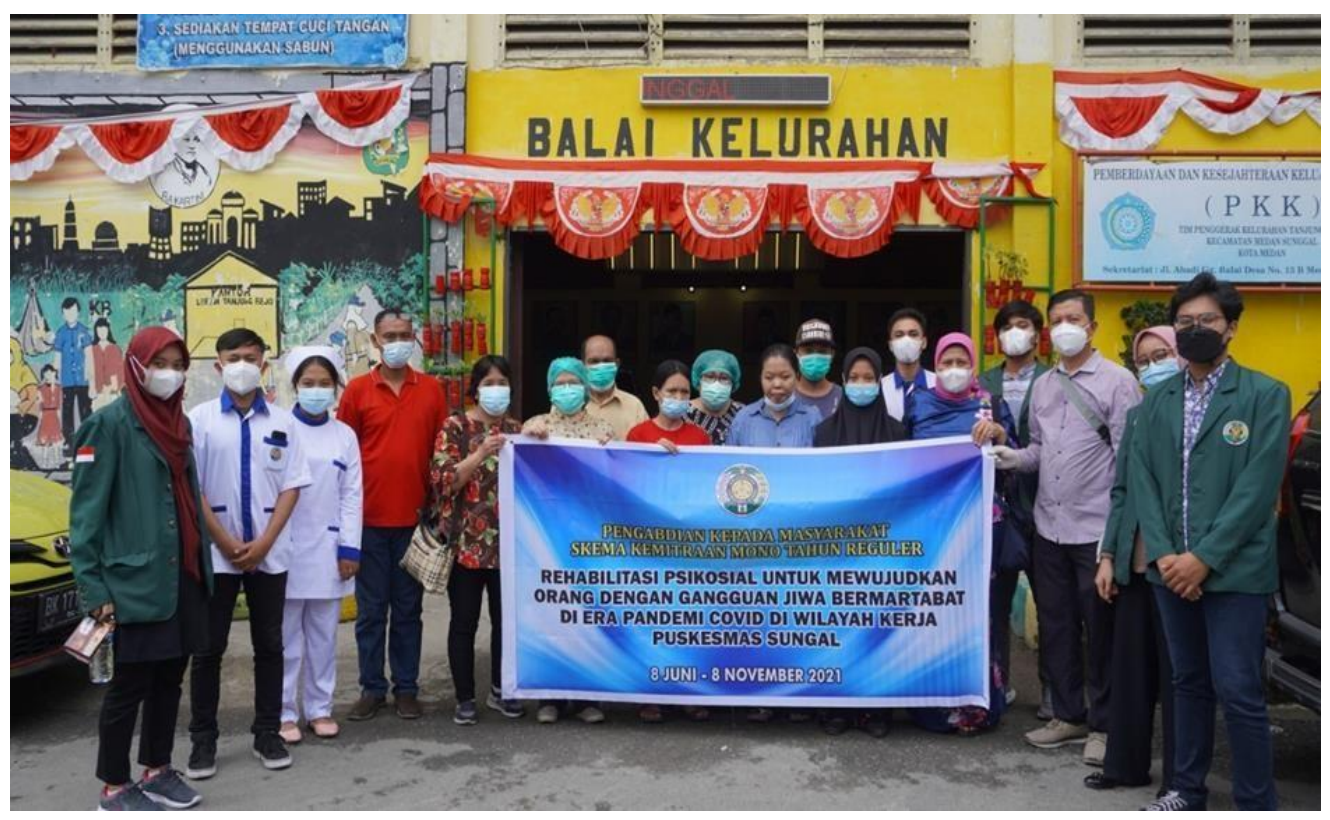

Gambar 2.3 Kegiatan PKM

\section{KESIMPULAN}

Rehabilitasi psikososial sangat dibutuhkan untuk mewujudkan ODGJ yang bermartabat sekaligus meningkatkan kualitas hidup mereka. Beberapa kegiatan dapat dilakukan sebagai implementasi rehabilitasi di era pandemi COVID 19. Pemberian edukasi tentang kepatuhan minum obat, pengembanganminat dan bakat serta pelatihan dasar pembuatan sabun cair memberikan dampak positif bagi peningkatan kognitif, afektif dan psikomotor orang dengan gangguan jiwa di komunitas.

\section{DAFTAR PUSTAKA}

D, H. (2012). Pendekatan Holistik (BPSS) Bio-psiko-Sosial-spiritual.

Hafifah, A., Puspitasari, I. M., \& Sinuraya, R. K. (2018). Review Artikel: Farmakoterapi dan Rehabilitasi Psikososial pada Skizofrenia. Farmaka, 16(2), 210-232.

Hawari, D. (2012). Skizofrenia: Pendekatan Holistik (BPSS) Bio-psiko-sosialspiritual. Edisi 3. Jakarta: Fakultas Kedokteran Universitas Indonesia

Kalogerakis, Z., Petroutsou, A., Chatzakis, A., Ploumpidis, D., Papageorgiou, C., \& Economou, M. (2019). Psychosocial rehabilitation and severe mental illness: Factors that influence patients' attendance in a support group. Psychiatriki, 30(2), 108-119.https: / / doi.org/10.22365/jpsych.2019.302.108

Magaru, M. (2012). \{ Formerly: Medical Sciences Bulletin \}. Pacific Journal of Medical Sciences, 11(2), 9-15.

Pardede, J. A. (2019). Terapi Rehabilitasi Pasien Gangguan Jiwa. Keperawatan Jiwa.

Purba, J. M., Simamora, R. H., \& Ginting, E. D. (2018). The Feasibility of a Home Care Management Model Based Coaching Intervention on Indonesian Caregivers' Outcomes of Relatives with Schizophrenia. 
Jurnal Keperawatan Soedirman, 13(2), 84. https: // doi.org/10.20884/1.jks.2018.13.2.832

Rasmus, P., Lipert, A., Pękala, K., Timler, M., Kozłowska, E., Robaczyńska, K., Sobów, T., Kozłowski, R., Marczak, M., \& Timler, D. (2021). The influence of a psychosocial rehabilitation program in a community health setting for patients with chronic mental disorders. International Journal of Environmental Research and Public Health, 18(8). https://doi.org/10.3390/ijerph18084319

Saha, S., Chauhan, A., Buch,B., Makwana, S., Vikar, S., Kotwani, P., \&Pandya, A. (2020). Psychsocial rehabilitation of people living with mentalillness: Lessons learnedfrom community-based psychiatricrehabilitation centres in Gujarat. Journal of Family Medicine and Primary care, 9(2),892-897

Wardhani, R.S., \& Asyanti, S. (2013). Penerimaan keluarga pasien skizofrenia yang menjalani rawat inap. Diakses dari http://eprints.ums.ac.id/ tanggal 5 November 2017

Williams, C. C., \& Tufford, L. (2012). Professional competencies for promoting recovery in mental illness. Psychiatry (New York), 75(2), 190- 201. https://doi.org/10.1521/psyc.2012.75.2.190

Yusuf, S.Kp., M. K. D. A. (2015). Rehabilitasi Masalah Psikososial dalam Keperawatan. Lokakarya Rehabilitasi Psikososial; Biro Koordinasi Kedokteran Masyarakat (BKKM) Fakultas Kedokteran Universitas Airlangga Dan Jaringan Rehabilitasi Psikosial (JRPI), Surabaya, 22 Agustus2015, 11. 